\section{Eqüidade em saúde: uma análise crítica de conceitos}

\author{
Health equity: a critical analysis of concepts
}

\section{Abstract}

Health inequalities have been studied mainly from an epidemiological perspective, with limited attention to conceptual issues. The terms "equity" and "equality" have often been used as synonyms, as have their opposites, "inequity" and "inequality". The few attempts to establish their meanings have been either purely descriptive or have failed to add to an understanding of the underlying dynamics in health-disease-related phenomena. The present essay explores the semantic series that includes difference, diversity, distinction, inequality, and inequity and its relationship to health phenomena in light of Perelman's concept of equity, Bourdieu's sociology, and some arguments in Heller's theory of justice, with the aim of contributing to the development of these concepts, while discussing their implications for policymaking in health.

Equity in Health; Health Inequalities; Concept Formation
Ligia Maria Vieira-da-Silva 1

Naomar de Almeida Filho 1

\section{Introdução}

A ocorrência de variações na distribuição de problemas de saúde pode ser considerada como um fenômeno universal e contemporâneo $1,2,3,4,5,6,7,8,9,10$. A despeito de controvérsias localizadas 11, o volume de estudos existentes sobre o tema 12,13 é, em primeiro lugar, indicativo de questões de investigação ainda não suficientemente elucidadas, particularmente no que diz respeito à determinação social das doenças $\mathrm{e}$ eventos relacionados à saúde 14 . Além disso, observa-se grande interesse em relação a esse tipo de pesquisa visando a subsidiar políticas públicas necessárias para superar a distribuição desigual de saúde na sociedade.

Na maioria dos estudos empíricos, não se observa maior preocupação dos autores em definir termos e estabelecer conceitos. As noções de eqüidade e igualdade, por um lado, e seus contrários, desigualdade, diferença e iniqüidade, são tratados como sinônimos. Mesmo nos trabalhos teóricos a respeito da temática 15,16,17, chamam a atenção a superposição e diversidade de significados atribuídos aos conceitos de diferença, disparidade, desigualdade, heterogeneidade $\mathrm{e}$ iniqüidade, revelando uma clara confusão terminológica. Não obstante, algumas tentativas têm sido feitas no sentido de precisar melhor esses conceitos 18,19,20,21,22,23.

Neste ensaio, pretendemos analisar criticamente a série significante diversidade, diferença, 
desigualdade, iniqüidade, distinção no que concerne à produção da saúde-doença em grupos sociais e nas suas possibilidades de articulação a uma teoria social da saúde. Nesse percurso, estaremos apoiados, por um lado, no conceito de Perelman de eqüidade e em alguns dos argumentos de Heller sobre a justiça e, por outro lado, na sociologia das práticas de Bourdieu, procurando discutir suas implicações para a formulação de políticas públicas no campo da saúde.

\section{Confusão conceitual}

Uma distinção freqüentemente encontrada na literatura é aquela entre eqüidade horizontal - que corresponderia ao tratamento igual de iguais - e eqüidade vertical - que corresponderia ao tratamento desigual de desiguais 14,24,25,26,27,28. Essa distinção, correspondente à importante contribuição aristotélica à cultura política do Ocidente, considera eqüidade como equivalente à justiça sempre referida a certa forma de igualdade. Aplicada ao financiamento em saúde, tem sido traduzida como um princípio geral, em que a contribuição para o financiamento dos serviços deve manter relação direta com a capacidade de pagamento do usuário.

Whitehead seguramente é a autora mais citada nos trabalhos da literatura internacional que empregam conceitos de eqüidade em saúde. Em 1990, Whitehead elaborou documento de consultoria para a Organização Mundial da Saúde (OMS), posteriormente publicado no International Journal of Health Services, no qual propunha distinguir diferenças ou disparidades em saúde (differences or disparities) de iniqüidades (inequities) em saúde 18,19. Para essa autora, iniqüidades constituem diferenças que, além de evitáveis, são também injustas 19. Em nota de rodapé, a autora explica que ela e a OMS não iriam utilizar o termo inequality devido à ambigüidade presente no uso do mesmo na literatura.

Alguns autores 24,28,29 definem iniqüidade como desigualdades injustas, sem, no entanto, citar Whitehead. Contudo, parte dos autores a citam de forma imprecisa, pois referem que ela distingue desigualdade (inequality) de iniqüidade (inequity) 20,26,27,30,31,32. Ao agirem assim, esses autores consideram desigualdade como sinônimo de diferença. Curiosamente, isso ocorre inclusive em artigos que trazem a própria Whitehead como co-autora 31,33 .

Com base nos trabalhos do filósofo, John Rawls, Peter \& Evans 34 desenvolvem teoricamente a idéia de justiça a que Whitehead apenas refere. Bastante influente na literatura atual sobre desigualdades em saúde, a teoria da justiça de
Rawls 35 propõe igualdade de oportunidades e também de distribuição de bens e serviços referentes a necessidades básicas. Nessa linha, Daniels et al. ${ }^{36}$ questionam a abordagem de Whitehead tanto no que diz respeito à "evitabilidade" quanto no que concerne à "justiça” pelo fato de que ambos os conceitos envolvem questões complexas e não resolvidas. No que diz respeito ao critério de justiça, esses autores o interpretam a partir da teoria de Rawls 35 , segundo a qual, a justiça está relacionada com igualdade de oportunidades, de liberdade, bem como distribuição igual dos principais determinantes da saúde. Outros trabalhos 27,28,37 também recorrem a teorias de justiça para avaliar o que seriam diferenças evitáveis e injustas.

Macinko \& Starfield 24 revisaram sistematicamente a bibliografia indexada no MEDLINE entre 1980 e 2001 e consideram que incluir justiça no conceito de eqüidade traz problemas operacionais tendo em vista que impõe o recurso a “julgamentos de valor”. Propõem então usar a definição de eqüidade adotada pela International Society for Equity in Health (ISEqH) segundo a qual "eqüidade corresponde à ausência de diferenças sistemáticas potencialmente curáveis (remediables) em um ou mais aspectos da saúde em grupos ou subgrupos populacionais definidos socialmente, economicamente, demograficamente ou geograficamente" 24 (p. 1). Essa concepção não distingue eqüidade de igualdade ao defini-la como "ausência de diferenças". Também, ao recusar entrar no debate sobre a justiça em saúde, tal posicionamento não enfrenta temas polêmicos sobre acesso e oferta de serviços, financiamento e formas de organização e controle de sistemas de saúde que constituem dilemas políticos concretos. E, finalmente, ao não explicitar qual o sentido atribuído ao conceito de "necessidades iguais", implica alguns problemas conceituais e operacionais. Por exemplo, o que significaria acesso igual para necessidades iguais? Seriam as necessidades de serviços de saúde de um trabalhador rural iguais às de um executivo? O que significa oferecer cuidado de igual qualidade para todos que tenham igual necessidade? Contudo, a definição do ISEqH tem vantagens operacionais pois, ao deslocar o problema das diferenças para o âmbito do controle técnico (diferenças curáveis), permite uma melhor identificação do que seriam situações iníquas para fins de intervenção.

Em uma abordagem histórico-estrutural, Breilh 21,22 propõe um conceito próprio de diversidade, que corresponderia à variação em características de uma população (gênero, nacionalidade, etnia, geração, cultura etc.). A diversidade, para esse autor, pode ter um sentido positivo em 
projetos sociais nos quais predominem relações solidárias e de cooperação entre gêneros e grupos étnicos. A “iniqüidade” seria, para Breilh 21,22, uma categoria analítica que marca a essência do problema da distribuição de bens na sociedade, enquanto a desigualdade corresponderia a evidências empiricamente observáveis. Quando a “iniqüidade" surge historicamente, a diversidade assume um papel negativo, tornando-se veículo de exploração e subordinação. O termo "iniqüidade", por sua vez, seria sinônimo de injustiça. As diferenças constituiriam a expressão, nos indivíduos, ou da diversidade, em sociedades solidárias, ou da iniqüidade, em sociedades em que haja concentração de poder 21,22.

Esses trabalhos constituem inegável contribuição à temática ao fundamentarem a relevância da análise conceitual nas investigações acerca de variações na saúde e no adoecer. A contribuição de Whitehead e seus seguidores relaciona-se com a introdução da idéia de justiça para distinguir iniqüidades de diferenças ou disparidades em saúde. Entretanto, o principal problema com a proposição de Whitehead 18 (p. 431) é que ela não apresenta nenhum conceito de justiça para fundamentar sua proposição das "diferenças evitáveis e injustas". Por outro lado, no momento em que interpreta "eqüidade no cuidado de saúde" (equity in health care) como "acesso igual para cuidado disponível para necessidades iguais" (equal access to available care for equal need) 18 (p. 434), acaba incorporando fórmulas implícitas de justiça abstrata no sentido de Perelman 38 (p. 9): "a cada qual a mesma coisa".

A superposição de igualdade e eqüidade feita por Whitehead e seus seguidores retira da noção de eqüidade sua função analítica precípua, conforme argumentação de Perelman ${ }^{38}$. Por outro lado, ao definir "necessidades iguais" como referencial para a eqüidade, parte de um pressuposto inexistente na prática, conforme mostrou Heller 39 em Além da Justiça. Já na versão modificada da proposição de Whitehead, ao igualar diferenças com desigualdades, seus autores desconhecem que, no pensamento dos principais filósofos políticos contemporâneos 38 , igualdade associa-se à justiça, e o seu oposto, desigualdade, à injustiça.

Em suma, todos esses enfoques revelam importantes inconsistências terminológicas e conceituais. Por um lado, a incorporação de teorias de justiça na análise das desigualdades em saúde tem sido incipiente na maioria dos estudos sobre o tema, exceção feita aos trabalhos de Daniels et al. 36 e Peter \& Evans 34 , conforme mencionado acima. Tal carência é crucial na medida em que as diversas teorias de justiça social implicam interpretações distintas sobre relações entre ne- cessidades e distribuição social dos serviços de saúde, bem como sobre natureza, formulação e implantação das políticas de saúde.

Por outro lado, teorias sociais que subsidiam a discussão conceitual dos determinantes sociais da saúde raramente têm sido desenvolvidas e explicitadas na profusa literatura sobre o tema 40,41 . Ambas as lacunas são centrais para a compreensão acerca do significado dos conceitos relacionados com diferenças na saúde-doença-cuidado em populações. Isso porque diferenças no estado de saúde de grupos e classes são resultantes de processos biológicos e sociais cuja explicação pode envolver diversas teorias sobre o social, com desdobramentos metodológicos e conceituais variados, a depender do referencial adotado.

Exceção parece ser a abordagem de Breilh 21,22 , de clara orientação marxista, que remete a uma análise do significado de variações e desigualdades na saúde e na doença frente às suas dimensões individuais e coletivas, situando-as historicamente em relação a agendas políticas específicas. Contudo, na abordagem de Breilh 21,22, a análise do conceito de diversidade não se baseia em nenhuma sociedade concreta, de forma que não fica claro se, ao lograrmos eliminar a concentração de poder nas mãos de grupos sociais, distribuir melhor a riqueza e também o acesso aos serviços de saúde, numa sociedade mais solidária, as diferenças em saúde restariam apenas biológicas.

\section{Eqüidade e justiça em saúde}

Importantes variações na distribuição das doenças em populações têm sido atribuídas às formas históricas através das quais os homens distribuem a riqueza em sociedades concretas. Tais disparidades se expressam por meio de renda, educação e classe social, correspondendo, nesse caso, à materialização de desigualdades. É inevitável a consideração de componentes culturais, éticos e políticos em qualquer avaliação teórico-epistemológica das raízes da diversidade, de qualquer natureza, nas sociedades humanas.

O conceito de igualdade tem sido relacionado com a noção de justiça no pensamento dos principais filósofos ocidentais, desde Aristóteles 38. Como desdobramento lógico, o conceito de desigualdade remete automaticamente à idéia de injustiça. Entretanto, associar simplesmente justiça e igualdade corresponderia a privilegiar apenas uma das modalidades da justiça formal, aquela que atribuiria "a cada qual a mesma coisa".

Perelman 38 (p. 9) sistematizou possíveis fórmulas de justiça segundo as quais os homens têm julgado seus semelhantes: "a cada qual segundo 
suas obras"; " a cada qual segundo seus méritos”; "a cada qual segundo suas necessidades"; "a cada qual segundo a lei”; " a cada qual segundo sua posição”. Na prática cotidiana, essas diversas fórmulas da justiça podem entrar em contradição. Por exemplo, se dois indivíduos, com a mesma qualificação (mérito), produzem, do ponto de vista qualitativo e quantitativo, diferentes bens (obras), pode não ser justa uma remuneração equivalente.

Eqüidade, no sentido que lhe é dado por Perelman 38 , corresponde a um instrumento da justiça concreta concebido para resolver as antinomias ou contradições entre as diversas fórmulas da justiça formal. A eqüidade corresponde, dessa forma, a uma intervenção de agentes sociais, quando assumem o papel de juiz, sobre situações de conflito. No caso específico da saúde, o exercício da eqüidade pode se materializar no processo de formulação das políticas de saúde e das políticas públicas intersetoriais que podem ter impacto sobre os determinantes sociais da saúde. Nesse sentido, eqüidade corresponderia à participação e governança determinada pela cidadania plena, em um contexto de liberdade e democracia. Ainda assim, precisaríamos definir melhor o que é cidadania plena. No caso brasileiro, por exemplo, os resultados das conferências de saúde mostram que ainda não alcançamos graus mínimos de cidadania. Independentemente disso, o Estado pode formular políticas mais ou menos promotoras de eqüidade.

Heller 39 critica as fórmulas que definem necessidades como critérios de justiça e apenas considera as primeiras três fórmulas, aquelas que envolvem trabalho, mérito e posição. Para Heller, necessidades humanas não podem ser definidas de forma objetiva, e definir necessidades iguais é, conseqüentemente, uma tarefa impossível. A partir de uma perspectiva diversa, Perelman 38 (p. 9) também tinha consciência de que a fórmula "a cada qual segundo suas necessidades" não era uma fórmula de justiça. Por essa razão, sugeriu alterá-la para "a cada qual de acordo com suas necessidades essenciais” 38 (p. 9). Isso é verdadeiro para todos os determinantes sociais da saúde, como comida, educação e situação no trabalho, entre outros. $\mathrm{O}$ alimento pode ser considerado como necessidade básica e universal. Entretanto, o tipo e quantidade variam de pessoa para pessoa, de cultura para cultura e de classe para classe. Há também necessidades humanas que não podem ser distribuídas, como, por exemplo, amor e amizade.

No campo da saúde, tal condição é plenamente aplicável. As necessidades de serviços de saúde e mesmo as necessidades de saúde variam de pessoa para pessoa. Se decidirmos aplicar a fórmula de Whitehead, de acesso igual para necessidades iguais, os problemas práticos serão insuperáveis. Quando uma criança tem uma pneumonia, precisa de uma consulta médica de emergência. Todavia, se a criança nasceu em uma família rica, seus pais somente considerarão que suas necessidades foram satisfeitas se o acesso for imediato a um hospital limpo, moderno e confortável. Se a mãe vem de família mais pobre, ela pode ficar satisfeita simplesmente ao ter acesso ao cuidado efetivo, em tempo hábil para a resolução do problema, com pouca preocupação com o tempo de espera ou se o hospital funciona num prédio sem conservação. Para a definição de políticas de saúde justas, que correspondam ao atendimento das necessidades da população, quais as necessidades que devem ser consideradas? As da mãe rica ou as da mãe pobre? Se, por razões econômicas e técnicas, consideramos as expectativas da mãe pobre, não estaremos satisfazendo as necessidades da mãe rica, e ela procurará assistência fora da rede pública com implicações para os propósitos de desenvolvimento de sistemas universais. Mais grave ainda, poderemos estar rebaixando a definição do cuidado aceitável às expectativas modestas das classes populares que ajustam, freqüentemente, necessidades a possibilidades, como analisou Bourdieu 42 em relação ao gosto popular.

Para resolver esse problema, Heller 39 (p. 52) substituiu a idéia de justiça relacionada com necessidades ou necessidades essenciais por aquela fórmula: "Para cada um, aquilo que lhe é devido por ser um membro de um grupo ou categoria essencial". Entretanto, mesmo se a fórmula "a cada qual segundo suas necessidades" não é uma idéia de justiça, ela pode ser aplicada como uma idéia de justiça corretiva, como uma idéia de igualdade. Em outras palavras, a pessoa que está julgando pode levar em conta a singularidade das necessidades pessoais e distribuir bens e serviços de diferentes formas para diferentes pessoas. Essa forma de ação pode ser boa, mas não justa. O conceito ético de justiça é, portanto, relacionado com as noções de honestidade $\mathrm{e}$ bondade.

Heller 39 também discute o conceito ético político de justiça como relacionado à tarefa, historicamente justificada tanto por fé como pela razão, de reformar tanto a sociedade injusta como os indivíduos injustos. Ela argumenta que, nos tempos modernos, o conceito ético de justiça perde seu componente sócio-político. O que resta é referido como justiça distributiva, que propõe liberdade igual, oportunidades iguais e acesso igual para recursos visando satisfazer as necessidades básicas essenciais ${ }^{42}$. Heller então conclui que igualdade e desigualdade são am- 
bos construtos sociais porque cada ser humano é único. Ela desenvolve um novo conceito ético político incompleto de justiça. Esse conceito tenta estabelecer uma base normativa comum para diferentes modos de vida. O conceito é incompleto porque cada modo de vida específico pode ser ideal para o indivíduo que o escolheu. É por essa razão que não pode existir um modo de vida ideal. Justiça, conclui Heller, existe como reciprocidade simétrica, comunicação e cooperação.

Na presente discussão, como vimos, ambos os termos "desigualdade" (inequality) e "iniqüidade" (inequity) devem ser relacionados a idéias de justiça de acordo com diferentes tradições teóricas. Assim, desigualdades em saúde podem ser interpretadas como resultado de diferentes formas de tratamento a indivíduos que pertencem a categorias essenciais ou grupos sociais 39,40 . Já eqüidade em saúde pode ser interpretada como o resultado de políticas que tratam indivíduos que não são iguais de forma diferente. Nesse sentido, "eqüidade" e "iniqüidade" correspondem a conceitos relacionados com a prática da justiça e à intencionalidade das políticas sociais e dos sistemas sociais.

\section{O conceito de distinção}

Um importante conceito a ser considerado nesta série significante, apesar de ausente no debate corrente sobre o tema desigualdades em saúde, envolve as dimensões simbólicas individuais e coletivas do existir humano. Trata-se da idéia de distinção, que será aqui utilizada no sentido proposto por Bourdieu 42 , referindo-se a um atributo que não é nem "natural" como pretende a burguesia nem necessariamente corresponde a diferenças sociais decorrentes de políticas iníquas produtoras de inferioridades. Analisando a homologia existente entre o espaço dos estilos de vida e o espaço social, através da investigação sobre o gosto das diferentes classes e frações de classe a respeito do consumo de bens culturais (obras de arte, cinema, música, lazer, esporte), mas também vitais (alimentação), esse autor conclui que o gosto constitui um operador prático da transformação de coisas em signos distintos e distintivos.

A distinção faz parte das práticas dos agentes sociais, quer de forma individual quer de forma coletiva, na constituição de sua identidade e de sua significação, o que não quer dizer que essa busca seja o motor da conduta humana como alerta o referido autor ${ }^{42}$. São então incorporadas à análise duas novas dimensões do problema: a natureza simbólica do homem 43 e o seu cotidiano 44. A dimensão simbólica introduz, na arena das variações sociais, um elemento mais propriamente dialógico ou interativo, referido à linguagem como mediador do valor (estético, religioso, mítico, esportivo etc.) das diferenças. Na dimensão do cotidiano, as opções mais ordinárias, como o gosto alimentar ou a prática de esportes, revestem-se de significado social relacionado com a constituição de classes sociais, classes de gênero e classes de geração.

Transportando essa reflexão para a saúde, poderíamos dizer, numa primeira aproximação, que diferenças biológicas produzem - para usar a expressão de Canguilhem 45 - potenciais de reação distintos frente às infidelidades do meio, resultando ou não em diferenças orgânicas, fisiopatológicas. Contudo, as diferenças biológicas, embora aparentemente dadas e naturais, sempre se expressam através de complexos processos de produção social. Se, por um lado, a expressão fenotípica e fenomênica dos processos biológicos resulta da interação entre o indivíduo e a sociedade, os mesmos podem, por sua vez, ser percebidos e ressignificados de forma diferente pelos sujeitos. Ou seja, as percepções e os sentidos atribuídos aos efeitos dos processos fenomênicos dependerão da posição que os sujeitos ocupam em diversos campos do espaço social, nos diferentes momentos históricos, bem como das relações estabelecidas com outros indivíduos no trabalho, na família e nos movimentos sociais. Embora essas relações sejam mais freqüentemente de luta e conflito, portanto geradoras de estresse, podem ser também cooperativas e comunicativas e, dessa forma, protetoras 46 .

Para Bourdieu 42, a matriz que orienta essas percepções e ressignificações é o habitus, esquemas de visão e de divisão do mundo social que funcionam como "estruturas estruturantes". Além disso, pelo fato de estarem relacionados à posição que os indivíduos ocupam num espaço social e com as diversas espécies de capital que o indivíduo acumula - econômico, cultural, social, político e simbólico, tais esquemas também conformam "estruturas estruturadas".

O conceito de habitus é central na teoria das práticas de Bourdieu juntamente com os conceitos de espaço social, campo, illusio e capital 42,47,48,49. O habitus corresponde à incorporação de estruturas relacionadas com a história coletiva e com a trajetória individual no inconsciente dos indivíduos. Dessa forma, funciona como esquemas de percepção e classificação das práticas, como um operador prático que ajusta condições objetivas a esperanças subjetivas. O habitus de classe ou de grupo corresponderia a um sistema subjetivo, mas não apenas individual, de estruturas interiorizadas 47 . 
Por outro lado, as práticas que implicam determinadas escolhas, gostos e estilos de vida e que influenciam na produção de certos estados orgânicos são o resultado da relação entre um habitus e uma situação ${ }^{42}$. Dessa forma, o processo saúde-doença-cuidado corresponderia ao produto de uma dupla relação entre os agentes sociais tanto na produção de certos estados orgânicos quanto nas percepções distintas acerca dos últimos. Ambos os complexos de fenômenos são influenciados pela posição ocupada pelo indivíduo no espaço social, pelas relações sociais de luta e cooperação existentes nas redes de relações dos campos a que eles pertencem e pelas dinâmicas existentes intra e entre campos sociais 46 .

\section{Semelhanças/diferenças no adoecer}

O processo concreto do adoecimento pode ser apreendido, numa primeira aproximação, como série fenomênica a um só tempo singular e particular, com grande variação entre indivíduos (ou espécimes), a despeito da existência de características comuns aos diversos casos de uma mesma doença. Consideremos como operador teórico dessa primeira aproximação a díade semelhança/diferença. Em segunda aproximação, doenças, padecimentos ou agravos à saúde são construídos como objeto de conhecimento científico, metodologicamente, por referência a variações em coletivos humanos. Nesse caso, estaríamos falando de igualdade/desigualdade de situações 38 , no opus operatum no sentido de Bourdieu ou no simples sentido da igualdade/ desigualdade matemática. No âmbito da saúde, a busca de semelhanças entre fenômenos da natureza - inspirada na lógica formal aristotélica 50 - tem norteado a construção de conceitos em ciências descritivas, tais como a Anatomia e a Histologia, nas ciências da função, como a Fisiologia e a Patologia, bem como nos campos de aplicação científica, como a Medicina e a Saúde Coletiva. Assim, da mesma forma que as diversas espécies animais e vegetais foram classificadas, as doenças também foram nomeadas mediante a identificação de sintomas e sinais comuns a certos indivíduos e a partir de quadros anátomo-patológicos correlacionados. Em sua obra O Nascimento da Clínica, Foucault 51 assinala a importância da Medicina das Espécies para a constituição histórica de um saber racional e instrumental sobre os fenômenos da saúde-doença-sofrimento-morte, na Europa Ocidental, no século XVIII.

As diferenças individuais entre distintas manifestações de certas patologias têm sido valo- rizadas principalmente pela clínica, que, nesse sentido, engendrou o aforismo idealizado - existem doentes e não doenças -. Numa perspectiva comparativa visando à produção de conhecimento de base indutiva, originalmente no nível subindividual da Patologia, importa mais a semelhança como operador lógico-conceitual do diagnóstico; por outro lado, no nível individual da prática clínica, ressalta-se a diferença entre os casos que demandam intervenção profilática ou terapêutica específica.

Por outro lado, ao se considerar a dimensão coletiva do fenômeno saúde-doença, priorizamse disparidades não entre seres individuais e sim entre conjuntos de indivíduos - "populações". Isso tem caracterizado a Epidemiologia, constituída, no século XX, como abordagem científica dos fenômenos populacionais da saúde-doença, registrando as diferenças, inicialmente em relação ao lugar, tempo, idade e sexo, e, posteriormente, em relação a estratos, grupos, etnias, gêneros e classes sociais. A busca de associações entre expostos e não expostos implica simultaneamente na identificação de semelhanças entre indivíduos e diferenças entre grupos.

A Epidemiologia, enquanto dispositivo tecnológico, pode até ser capaz de medir com algum grau de precisão variações na mortalidade e na morbidade, porém encontra limitações para explicar as raízes das disparidades sociais em saúde e sua persistência mesmo em sociedades industrializadas. De fato, o estudo das desigualdades em saúde implica adoção de um referencial teórico capaz de relacionar essas diferenças com os processos através dos quais o espaço social é constituído e reproduzido tanto na esfera econômica quanto na simbólica e cultural que podem resultar tanto em apropriação material da riqueza, a partir da exploração do trabalho de um grupo por outro, quanto em violência simbólica, gerando, assim, diferenças que, por serem produto de injustiças, correspondem a desigualdades.

Como ilustração, tomemos o campo da Genética, responsável pelos exemplos mais consistentes de reafirmação das diferenças biológicas entre os seres humanos. Mesmo em relação a essa ordem de determinação, as características de penetrância e expressividade dos genes traduzem a variabilidade dos mesmos bem como sua expressão concreta como produto da interação com o meio 52 . Uma criança com síndrome de Down pode, a depender da rede de relações sociais estabelecida pela família e pela sociedade, desenvolver atividades habituais e até mesmo artísticas. Pelo contrário, outra criança com quadro congênito similar, cuja posição no espaço social não lhe permite superar seu problema genético e ser normativa (no sentido canguilhemiano), 
dependerá de políticas equânimes de saúde para que a diferença biológica não resulte em um problema de saúde. Nesse caso, a diferença biológica, na ausência de eqüidade, pode tornar-se desigualdade.

Também outras diferenças biológicas, e também socialmente construídas, consideradas no plano coletivo como diversidade, no sentido proposto por Breilh 21,22, e que repercutem na saúde (gênero, etnia e geração), são influenciadas e mediadas por diferenças sociais. A cronificação de idosos relacionada com o abandono familiar pode estar relacionada com as características das relações familiares que variam, entre outros aspectos, com os grupos sociais. As repercussões e a capacidade de enfrentamento da violência doméstica contra a mulher, fruto da dominação de gênero que estrutura a sociedade ocidental, variam também entre campos do espaço social. Quanto mais bem situada no espaço social no que diz respeito à quantidade de capital cultural, econômico e simbólico acumulados, a mulher dispõe de mais recursos para enfrentar a violência masculina, quer materialmente, quer psicologicamente.

Em outras palavras, a pergunta que motiva grande parte das investigações de causalidade na Epidemiologia é exatamente quais são os atributos comuns ao grupo doente e quais as diferenças em relação ao grupo que não adoece. A resposta a essa questão tem sido norteada, de forma hegemônica, por uma concepção biologicista da determinação das doenças e pelo recurso ao conceito formal de risco como probabilidade de adoecer 53. Assim, o esforço de mapeamento do genoma humano, as tentativas de isolamento de novos vírus em doenças neoplásicas e a chamada epidemiologia molecular situam-se nessa direção 54. Segundo tal abordagem, homens e mulheres, negros e brancos, ricos e pobres adoeceriam porque são constitutivamente diferentes entre si, têm genótipos diversos e, conseqüentemente, desenvolvem respostas imunes diferenciadas - em outras palavras -, tratam-se de substâncias diferentes. Não poderia haver melhor exemplo, a ser frontalmente questionado, de uma visão substancialista da ciência, no sentido de Cassirer 50.

\section{Conceitos de Eqüidade em Saúde: conclusão}

À exceção da proposta de Breilh 21,22, as perspectivas analisadas acima situam os conceitos da série semântica em pauta num mesmo patamar hierárquico, como se fossem expressões de processos sociais históricos equivalentes, o que im- pede politizar os seus diversos sentidos e efeitos. A presente proposta de abordagem do problema da eqüidade em saúde, pelo contrário, possibilita reafirmar que as diferenças de ocorrência de doenças e eventos relativos à saúde são mediadas social e simbolicamente. Desse modo, refletem interações entre diferenças biológicas e distinções sociais por um lado e iniqüidades sociais por outro, tendo como expressão empírica as desigualdades em saúde. Por esse motivo, tratar teoricamente o problema da eqüidade em saúde toma como imperativo examinar as práticas humanas, sua determinação e intencionalidade no que diz respeito especificamente a situações concretas de interação entre os sujeitos sociais.

No plano metodológico, algumas das contribuições dos autores aqui analisados podem ser úteis para estabelecer uma terminologia mais precisa no sentido de construir uma matriz semântica comum, passo inicial para melhores práticas de pesquisa sobre o tema injustiças em saúde. Nesse sentido, identificamos a oportunidade e mesmo urgência de restaurar as relações teóricas entre os conceitos a fim de possibilitar uma prática social transformadora.

As considerações feitas aqui sobre a natureza das iniqüidades em saúde mostram que, além disso, é necessária uma reorganização do espaço social, sua estrutura e suas relações. Essa tese, entretanto, pressupõe a existência de atos desinteressados combinada com ações racionalmente direcionadas a finalidades explicitamente apresentadas. A unanimidade do discurso em prol da eqüidade, não obstante o amplo espectro de forças políticas que o formulam, ao tempo em que se contempla a persistência das desigualdades no mundo, mostra que outras lógicas devem estar orientando a formulação (ou pelo menos a implementação) das políticas públicas.

$\mathrm{Na}$ atual conjuntura de debate teórico da Saúde Coletiva no Brasil, tornou-se consenso afirmar que a superação das desigualdades em saúde requer a formulação de políticas públicas equânimes. Isso corresponde ao reconhecimento da saúde como direito e à priorização das necessidades como categoria essencial para as formas de justiça. Priorizar necessidades não significa impor necessidades, porém definir o padrão tecnicamente aceitável interagindo com as expectativas dos diversos modos de vida dos diferentes grupos sociais. Introduzir, no debate da saúde, o conceito de distinção, tal como definido por Bourdieu 42, significa incorporar, na pauta política da Saúde Coletiva, aquelas diferenças e diversidades que, por se situarem predominantemente no plano simbólico, apareciam como mero resíduo da vida social dos 
seres humanos, como, por exemplo, a questão das condutas de risco e das heterogeneidades de base étnico-cultural.

À guisa de conclusão, embora este ensaio não pretenda ser um estudo semântico aprofundado e sim tão somente uma anotação para abertura de debate, portanto descomprometido com prescrições e soluções, afirmamos que a temática das desigualdades em saúde, marcada pela iniqüidade das políticas econômicas e sociais, impõe uma tomada de posição tanto epistemológica quanto política. Não basta ex- plicar o real para transformá-lo. Parafraseando Bourdieu 55 (p. 736) a respeito do conhecimento científico, diríamos que "a alternativa da ciência não é entre a desmedida totalizadora de um racionalismo dogmático e a renúncia esteta de um irracionalismo niilista; ela se satisfaz com verdades parciais e provisórias que ela pode conquistar contra a visão comum e contra a doxa intelectual e que estão em condições de fornecer os únicos meios racionais de utilizar plenamente as margens de manobra deixadas para a liberdade, isto é, para a ação política".

\section{Resumo}

A eqüidade em saúde tem sido estudada principalmente a partir de uma perspectiva epidemiológica e pouca atenção tem sido dada às questões conceituais. Em grande parte dos estudos revisados, a eqüidade tem sido utilizada como sinônimo de igualdade, e seu oposto, a iniqüidade, como sinônimo de desigualdade. As tentativas de melhor precisar seus significados têm sido, em boa parte, descritivas, com lacunas no que diz respeito à discussão das relações entre eqüidade em saúde, justiça e o processo de determinação social da saúde-doença. Neste ensaio, pretendemos analisar criticamente a série significante diversidade, diferença, desigualdade, iniqüidade, distinção no que concerne à produção da saúde-doença-cuidado em grupos sociais e suas possibilidades de articulação a uma teoria social da saúde. Nesse percurso, estaremos apoiados, por um lado, no conceito de Perelman de eqüidade e em alguns dos argumentos de Heller sobre a justiça e, por outro lado, na sociologia das práticas de Bourdieu, com o objetivo de melhor desenvolver esses conceitos, procurando discutir implicações para a formulação de políticas públicas no campo da saúde.

Eqüidade em Saúde; Desigualdade em Saúde; Formação de Conceito

\section{Colaboradores}

L. M. Vieira-da-Silva foi responsável pela concepção da arquitetura do ensaio, realização da síntese da bibliografia revisada e redação. N. Almeida Filho contribuiu na concepção do ensaio, na síntese da bibliografia e na redação. 


\section{Referências}

1. Black D, Morris JN, Smith C, Townsend P. Inequalities in health. The black report. New York: Penguin/London: Pelikan; 1982.

2. Kunst AE, Mackenbach J. The size of mortality differences associated with educational level in nine industrialized countries. Am J Public Health 1994; 84:932-7.

3. Backlund E, Sorlie PD, Johnson NJ. The shape of the relationship between income and mortality in the United States. Evidence from the National Longitudinal Mortality Study. Ann Epidemiol 1996; 6:12-20.

4. Fox J, Benzeval M. Perspectives on social variations in health. In: Benzeval M, Judge K, Whitehead M, editors. Tackling inequalities in health. An agenda for action. London: King's Fund; 1995. p. 10-21.

5. Marmot M, Ryff CD, Bumpass LL, Shipley M, Marks NF. Social inequalities in health: next questions and converging evidence. Soc Sci Med 1997; 44:901-10.

6. Vieira-da-Silva LM, Paim JS, Costa MCN. Desigualdades na mortalidade, espaço e estratos sociais em uma Capital da Região Nordeste. Rev Saúde Pública 1999; 33:187-97.

7. Cambois E, Robine J. Social inequalities in disability free life expectancy in France: results and methodological issues. Med Sci (Paris) 2000; 16:1218-24.

8. Kennedy B, Kawachi I, Prothrow-Stith D. Income distribution and mortality: cross sectional ecological study of the Robin Hood index in the United States. BMJ 1996; 312:1004-7.

9. Puigpinos R, Borrell C, Pasarin M, Montella N, Perez G, Plasencia A, et al. Inequalities in mortality by social class in men in Barcelona, Spain. Eur J Epidemiol 2000; 16:751-6.

10. Mackenbach JP. Income inequality and population health. BMJ 2002; 324:1-2.

11. Macinko JA, Sh L, Starfield B, Wulu JJT. Income inequality and health: a critical review of the literature. Med Care Res Rev 2003; 60:407-52.

12. Stronks K, van Trirum H, Mackenbach JP. A documentation centre on socioeconomic inequalities in health. J Epidemiol Community Health 1996; 50:5.

13. Almeida-Filho N, Kawachi I, Pellegrini A, Dachs JNW. Research on health inequalities in Latin America and the Caribbean: Bibliometric analysis (1971-2000) and descriptive content analysis (1971-1995). Am J Public Health 2003; 93:2037-43.

14. Wagstaff A, Doorslaer EV. Income inequality and health. What does the literature tells us? Annu Rev Public Health 2000; 21:543-67.

15. Wilkinson RG. Unhealthy societies. The afflications of Inequality. London: Routledge; 1996.

16. Castellanos PL. Epidemiologia, saúde pública, situação de saúde e condições de vida: considerações conceituais. In: Barata $\mathrm{RB}$, organizador. Condições de vida e situação de saúde. Rio de Janeiro: ABRASCO; 1997. p. 31-75.

17. Feinstein JS. The relationship between socioeconomic status and health: a review of the literature. Milbank Q 1993; 71:279-322.
18. Whitehead M. The concepts and principles of equity and health. Int J Health Serv 1992; 22:429-45.

19. Whitehead M. The concept and principles of equity and health. Washington DC: Pan American Health Organization; 1991.

20. Ossanai J. Reformas contemporáneas en el campo de la salud: en busca de la equidad. Rockville: Technical Resources International Inc.; 1994.

21. Breilh J. Hacia una epidemiología dura: retos y avances. Quito: Casa de la Cultura Ecuatoriana; 1997.

22. Breilh J. La inequidad y la perspectiva de los sin poder: construcción de lo social y del género. In: Breilh J, editor. Cuerpos, diferencia y desigualdades. Bogotá: Utópica Ediciones; 1998.

23. Braverman P. Health disparities and health equity. Annu Rev Public Health 2006; 27:167-94.

24. Macinko JA, Starfield B. Annotated bibliography on equity in health, 1980-2001. Int J Equity Health 2002; $1: 1$.

25. Starfield B. Comment: health systems' effects on health status-financing vs the organziation of services. Am J Public Health 1995; 85:1350-1.

26. Alleyne GAO. Equity and health in equity and health: views from the Pan American Sanitary Bureau. Washington DC: Pan American Health Organization; 2001.

27. Bambas A, Casas JA. Assessing equity in health: conceptual criteria. In: Pan American Health Organization, editor. Equity and health. Views from the Pan American Sanitary Bureau. Washington DC: Pan American Health Organization; 2001. p. 12-21. (Ocasional Publication, 8)

28. Nunes A, Santos JRS, Barata RB, Viana SM. Medindo as desigualdades em saúde no Brasil. Brasília: Organização Pan-Americana da Saúde/Instituto de Pesquisa Econômica Aplicada; 2001.

29. Leon DA, Walt G, Gilson L. International perspectives on health inequalities and policy. BMJ 2001; 322:591-4

30. Braveman P, Tarimo E. Social inequalities in health within countries: not only an issue for affluent nations. Soc Sci Med 2002; 54:1621-35.

31. Evans T, Whitehead M, Diderichsen F, Bhuiya A, Wirth M. Introduction. In: Evans T, Whitehead M, Diderichsen F, Bhuiya A, Wirt M, editors. Challenging inequities in health: from ethics to action. New York: Oxford University Press; 2000. p. 3-44.

32. Metzger X. Conceptualización e indicadores para el término equidad y su aplicación en el campo de la salud. Washington DC: Organización Panamericana de la Salud; 1996.

33. Blank N, Diderichsen F. Inequalities in health: the interaction between socio-economic and personal circumstances. Public Health 1996; 110:157-62.

34. Peter F, Evans T. Ethical dimensions of health equitiy. In: Evans T, Whitehead M, Diderichsen F, Bhuiya A, Wirt M, editors. Challenging inequities in health: from ethics to action. New York: Oxford University Press; 2000. p. 25-33.

35. Rawls J. Justiça como eqüidade: uma reformulação. São Paulo: Editora Martins Fontes; 2003. 
36. Daniels N, Kennedy B, Kawachi I, Cohen J, Rogers J. Is inequality bad for our health? Boston: Beacon Press; 2000.

37. Stepke FL. Ética, equidad y práctica en las instituciones de salud. In: Pan American Health Organization, editor. Equity and health. Views from the Pan American Sanitary Bureau. Washington DC: Pan American Health Organization; 2001. p. 150-7. (Ocasional Publication, 8).

38. Perelman C. Ética e direito. São Paulo: Editora Martins Fontes; 1996.

39. Heller A. Além da justiça. Rio de Janeiro: Editora Civilização Brasileira; 1998.

40. Forbes A, Wainwright SP. On the metodological, theoretical and philosophical context of health inequalities research: a critique. Soc Sci Med 2001; 53:801-16.

41. Wainwright SP, Forbes A. Philosophical problems with social research on health inequalities. Health Care Anal 2000; 8:259-77.

42. Bourdieu P. La distinction. Critique social du jugement. Paris: Minuit; 1979.

43. Cassirer E. Ensaio sobre o homem. Lisboa: Guimarães Editores; 1995. (Coleção Filosofia \& Ensaio).

44. Heller A. Sociología de la vida cotidiana. Barcelona: Península Editorial; 1977.

45. Canguilhem G. Le normal et le pathologique. Paris: Presse Universitaire de France; 1966.
46. Vieira-da-Silva LMV, Dussault G. Santé, espace social et pratiques. Ruptures 1999; 6:192-208.

47. Bourdieu P. Le sens pratique. Le sens comun. Paris: Minuit; 1980.

48. Bourdieu P. Esquisse d'une theorie de la pratique. Geneva: Librairie Droz; 1972.

49. Bourdieu P. Razões práticas. Sobre a teoria da ação. Campinas/São Paulo: Editora Papirus; 1997.

50. Cassirer E. Substance and function and Einstein's theory of relativity. Chicago: Dover Publications; 1953.

51. Foucault M. O nascimento da clínica. Rio de Janeiro: Editora Forense-Universitária; 1977.

52. Baird PA. The role of genetics in population health. In: Evans RG, Baren ML, Marmor TR, editors. Why are some people healthy and others not? The determinants of health of populations. New York: Aldine de Gruyter; 1994.

53. Almeida-Filho ND. La ciencia tímida - ensayos de deconstrucción de la epidemiologia. Buenos Aires: Editorial Lugar; 2000.

54. Castiel LD. A medida do possível... saúde, risco e tecnobiociências. Rio de Janeiro: Editora Fiocruz; 1999.

55. Bourdieu P, Accardo A, Balazs G, Beaud S, Bourdieu E, Bourgois P, et al. A miséria do mundo. 2a Ed. Petrópolis: Editora Vozes; 1998.

Recebido em 11/Mar/2008

Aprovado em 17/Jun/2008 